\title{
HDlive Flow with HDlive Silhouette for Diagnosis of Velamentous Cord Insertion
}

\author{
Toshiyuki Hata $^{1}$, Tomomi Kawahara ${ }^{2}$, Miyu Konishi ${ }^{3}$, Saori Bouno ${ }^{4}$, Tomomi Yamanishi ${ }^{5}$, Aya Koyanagi ${ }^{6}$, \\ Riko Takayoshi ${ }^{7}$, Takahito Miyake ${ }^{8}$
}

\begin{abstract}
Velamentous cord insertion is often associated with various complications during pregnancy and labor. Color Doppler ultrasound is a useful diagnostic tool for the prenatal diagnosis of velamentous cord insertion. HDlive flow with HDlive silhouette is the latest imaging modality consisting of power Doppler and grayscale technologies, and it provides additional information on normal and abnormal placental and umbilical cord blood flow. In the first case of velamentous cord insertion, HDlive flow with HDlive silhouette clearly showed a fork-like attachment of the umbilical cord on the fetal membrane near the placenta. In the second case of accenturiate placenta with velamentous cord insertion, HDlive flow with HDlive silhouette clearly revealed the number and direction of aberrant vessels on the fetal membrane connected to both placentas (mangrove-like attachment of umbilical cord). HDlive flow with HDlive silhouette may be a useful diagnostic modality for the precise prenatal diagnosis of velamentous cord insertion.

Keywords: Accenturiate placenta, Fork-like attachment of umbilical cord, HDlive flow, HDlive silhouette, Mangrove-like attachment of umbilical cord, Velamentous cord insertion.

Donald School Journal of Ultrasound in Obstetrics and Gynecology (2021): 10.5005/jp-journals-10009-1809
\end{abstract}

\section{INTRODUCTION}

Prenatal diagnosis of velamentous cord insertion may help to prevent various perinatal complications such as fetal growth restriction, preterm delivery, intrapartum nonreassuring fetal heart rate pattern, low Apgar scores, neonatal death, and abruptio placenta during pregnancy and labor. ${ }^{1}$ Two-dimensional (2D) sonography and color Doppler ultrasound can reliably detect velamentous cord insertion prenatally, whereas three-dimensional (3D) ultrasound (3D rendering mode) can provide only limited information to evaluate the placental cord insertion. ${ }^{2}$

HDlive flow with HDlive silhouette is the latest power Doppler and grayscale technologies, and it provides useful additional information to diagnose fetal blood vessel and tumor vascularity, ${ }^{3,4}$ and normal and abnormal placental and umbilical cord blood flow. ${ }^{5}$ In this study, we assess the usefulness of HDlive flow with HDlive silhouette for the evaluation of velamentous cord insertion.

\section{CASE 1}

A 32-year-old pregnant Japanese woman, gravida 1, para 0 , received routine early third-trimester screening at 28 weeks and 2 days of gestation, and marginal or velamentous cord insertion was suspected. Two weeks later, cross-examination was performed to assess the exact cord insertion site. 2D sonography and power Doppler ultrasound confirmed the velamentous cord insertion near the placenta (Figs 1 and 2). HDlive flow with HDlive Silhouette clearly showed fork-like attachment of the umbilical cord on the fetal membrane, and three aberrant vessels were noted (Fig. 3).

At 40 weeks and 4 days of gestation, emergency cesarean section was performed due to a nonreassuring fetal heart rate
$1,7,8$ Department of Obstetrics and Gynecology, Miyake Clinic, 369-8 Ofuku, Minami-ku, Okayama, Japan; Department of Perinatology and Gynecology, Kagawa University Graduate School of Medicine, 1750-1 Ikenobe, Miki, Kagawa, Japan

${ }^{2-6}$ Department of Obstetrics and Gynecology, Miyake Clinic, 369-8 Ofuku, Minami-ku, Okayama, Japan

Corresponding Author: Toshiyuki Hata, Department of Obstetrics and Gynecology, Miyake Clinic, 369-8 Ofuku, Minami-ku, Okayama, Japan; Department of Perinatology and Gynecology, Kagawa University Graduate School of Medicine, 1750-1 Ikenobe, Miki, Kagawa, Japan; Phone: +81-(0)87-891-2174, +81-(0)86-282-5100; +81-(0)86-281-3033, e-mail: toshi28@med.kagawa-u.ac.jp; hata@miyakegroup.jp

How to cite this article: Hata T, Kawahara T, Konishi M, et al. HDlive Flow with HDlive Silhouette for Diagnosis of Velamentous Cord Insertion. Donald School J Ultrasound Obstet Gynecol 2021;15(4):326-329.

Source of support: Nil

Conflict of Interest: None

pattern, resulting in a single male newborn weighing $2776 \mathrm{gm}$, with a length of $50 \mathrm{~cm}$. The umbilical artery $\mathrm{pH}$ was 7.37. The Apgar score was $9 / 10$ at 1 and 5 minutes, respectively. Total blood loss during the operation was $598 \mathrm{gm}$. Placental examination revealed its weight to be $669 \mathrm{gm}$, and it showed fork-like attachment of the umbilical cord on the fetal membrane with three very short aberrant vessels (Fig. 4).

\section{CASE 2}

A 38-year-old pregnant Japanese woman, gravida 3, para 1, received routine obstetric examination at 32 weeks and 2 days of gestation. 2D sonography revealed an anterior-implanted accenturiate placenta and velamentous cord insertion between the anterior and

(OTheAuthor(s). 2021 Open Access This article is distributed under the terms of the Creative Commons Attribution 4.0 International License (https://creativecommons. org/licenses/by-nc/4.0/), which permits unrestricted use, distribution, and non-commercial reproduction in any medium, provided you give appropriate credit to the original author(s) and the source, provide a link to the Creative Commons license, and indicate if changes were made. The Creative Commons Public Domain Dedication waiver (http://creativecommons.org/publicdomain/zero/1.0/) applies to the data made available in this article, unless otherwise stated. 


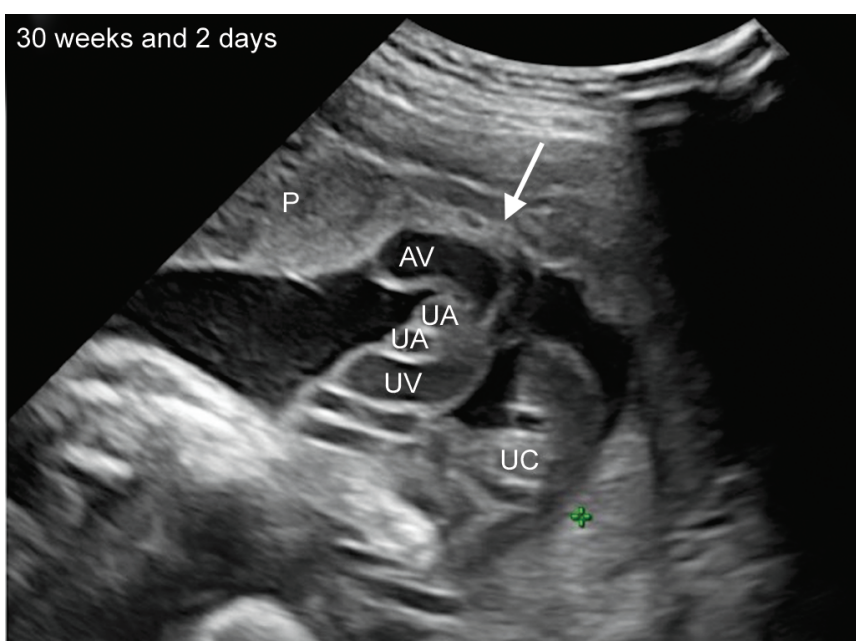

Fig. 1: Two-dimensional sonographic image of velamentous cord insertion (arrow) at 30 weeks and 2 days of gestation (AV: aberrant vessel; P: placenta; UA: umbilical artery; UC: umbilical cord; UV: umbilical vein)

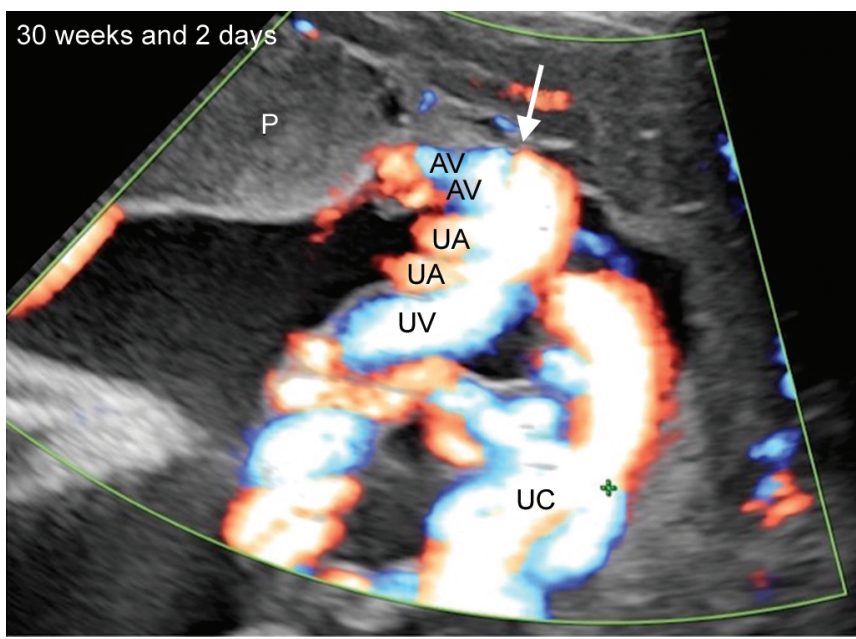

Fig. 2: Power Doppler ultrasound image of velamentous cord insertion (arrow) at 30 weeks and 2 days of gestation. Two aberrant vessels (AV) on the fetal membrane are noted (P: placenta; UA: umbilical artery; UC: umbilical cord; UV: umbilical vein)

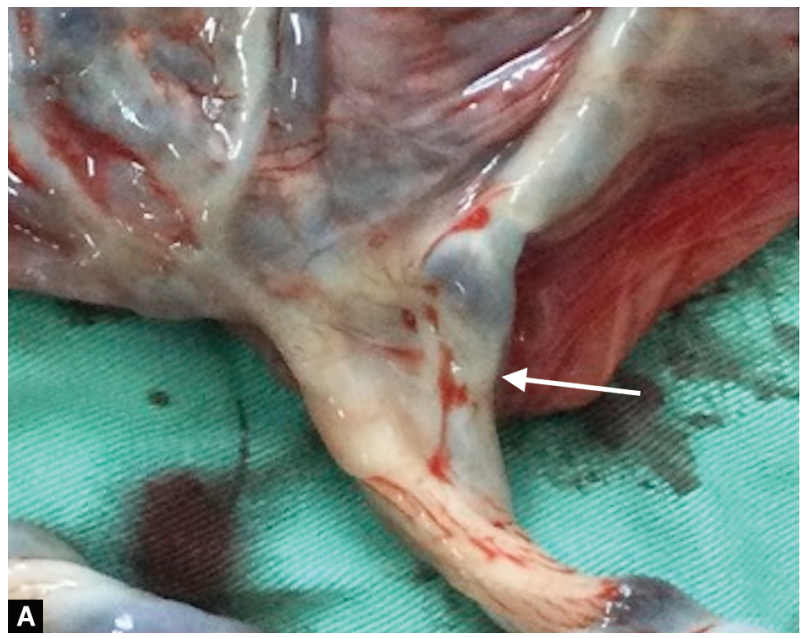

Figs 4A and B: Gross examination of velamentous cord insertion (arrows). Three aberrant vessels on the fetal membrane are clearly noted (A: Fetal surface; B: Maternal surface)

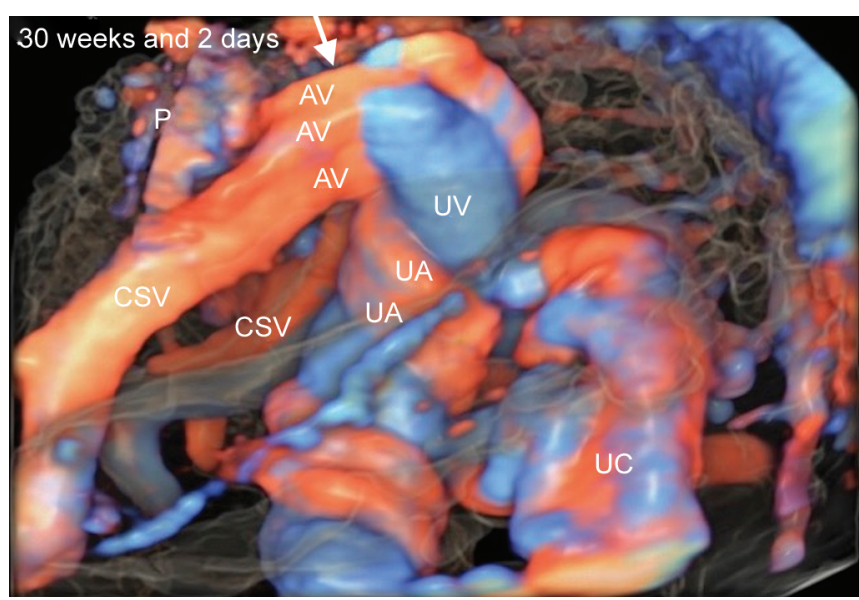

Fig. 3: Velamentous cord insertion (arrow) depicted by HDlive flow with HDlive silhouette at 30 weeks and 2 days of gestation. Three aberrant vessels (AV) on the fetal membrane are clearly identified (CSV: chorionic surface vessel; P: placenta; UA: umbilical artery; UC: umbilical cord; UV: umbilical vein)

posterior implanted placentas (Fig. 5). Power Doppler ultrasound showed the umbilical cord attached to the fetal membrane and aberrant vessels connected to both placentas (Fig. 6). HDlive flow with HDlive silhouette clearly revealed the number and direction of aberrant vessels on the fetal membrane connected to the anterior and posterior placentas (mangrove-like attachment of umbilical cord) (Fig. 7).

One female newborn was vaginally delivered at 39 weeks and 1 day of gestation with a body weight of $3100 \mathrm{gm}$ and length of $49 \mathrm{~cm}$. The umbilical artery $\mathrm{pH}$ was 7.32 . She had an Apgar score of $8 / 9$ at 1 and 5 minutes, respectively. Placental examination revealed a weight of $555 \mathrm{gm}$, accenturiate placenta, and velamentous cord insertion between the main and accenturiate placentas (mangrove-like attachment of umbilical cord) (Fig. 8).

\section{Discussion}

Conventional 3D power Doppler ultrasound had limited clinical value for the diagnosis of velamentous cord insertion. ${ }^{6}$ Regarding HDlive flow with HDlive silhouette, however, HDlive silhouette delineates

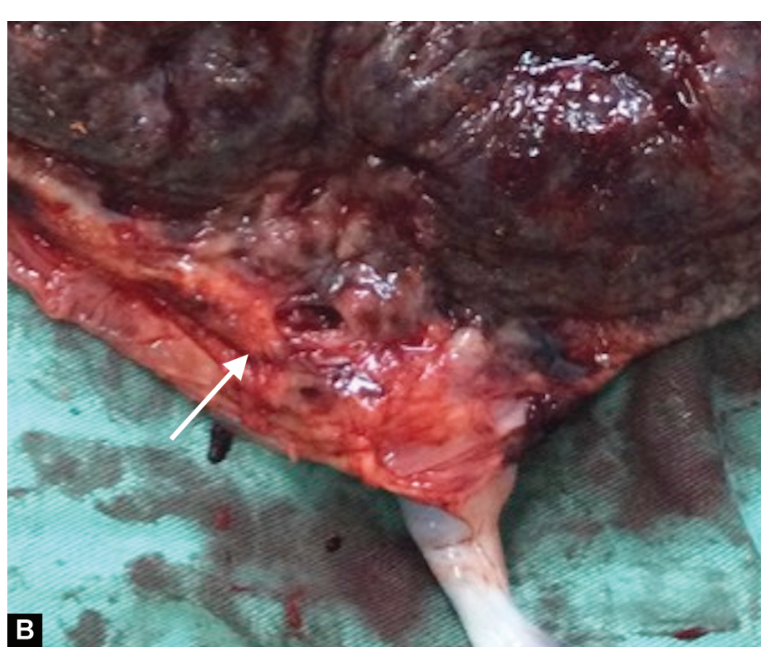

B 


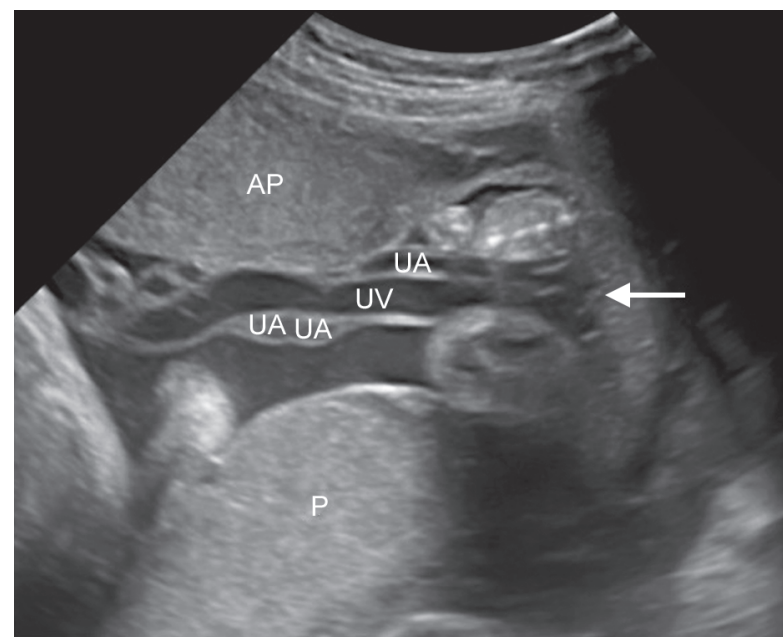

Fig. 5: Two-dimensional sonographic image of velamentous cord insertion (arrow) at 32 weeks and 2 days of gestation (AP: accenturiate placenta; P: placenta; UA: umbilical artery; UC: umbilical cord; UV: umbilical vein)
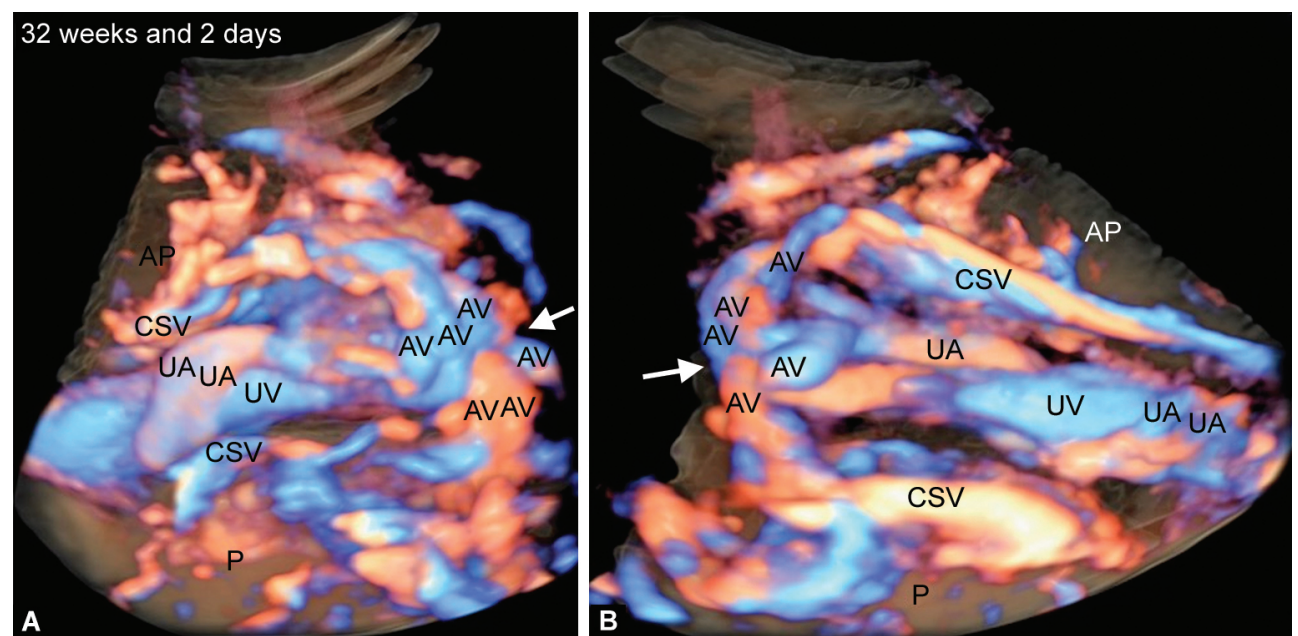

Figs. 7A and B: Velamentous cord insertion (arrows) depicted by HDlive flow with HDlive silhouette at 32 weeks and 2 days of gestation. The number and direction of aberrant vessels (AV) on the fetal membrane connected to accenturiate (AP) and main placentas (P) is clearly noted using HDlive flow with HDlive silhouette (CSV: chorionic surface vessel; UA: umbilical artery; UV: umbilical vein; $(a=A$ : Frontal; $b=B$ : Posterior)

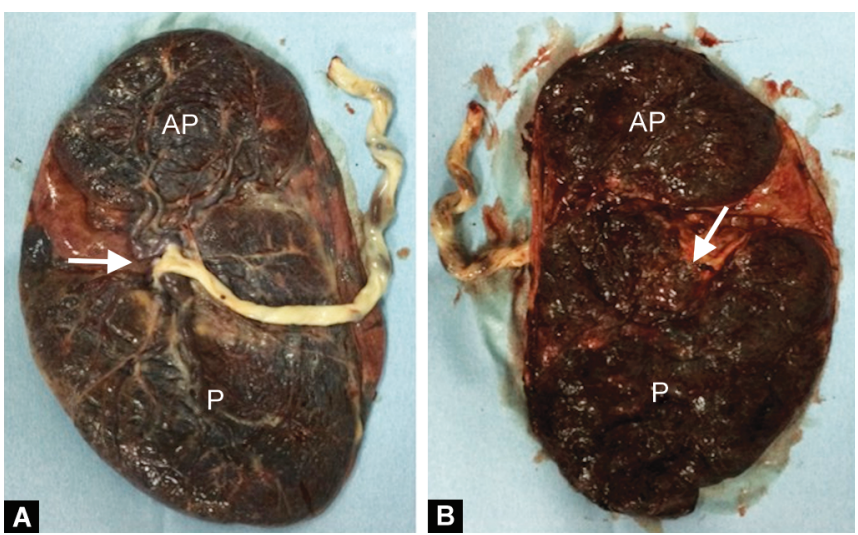

Figs $8 \mathrm{~A}$ and B: Gross examination of velamentous cord insertion (arrows) between the main $(\mathrm{P})$ and accenturiate (AP) placentas (mangrove-like attachment of umbilical cord) (A: Fetal surface; B: Maternal surface) the contour of the fetus and placenta with semitranslucency, and HDlive flow can demonstrate 3D reconstruction of fetal and placental vasculature when combined with an HDlive silhouette image. $^{3-5}$ Both techniques allow marked depth perception with valid shadowing effects. In the present study, HDlive flow with HDlive silhouette clearly showed fork-like attachment of the umbilical cord on the fetal membrane near the placenta in the first case of a velamentous cord, and revealed the number and direction of aberrant vessels on the fetal membrane connected to the main and accenturiate placentas (mangrove-like attachment of umbilical cord) in the second case. These features might not be visualizable on using conventional 3D power Doppler ultrasound. HDlive flow with HDlive silhouette may be a useful diagnostic technique for the comprehensive diagnosis of velamentous cord insertion in utero. Further studies involving a larger sample size are needed to confirm the clinical value of HDlive flow with HDlive silhouette for the diagnosis of abnormal placental cord insertion involving velamentous cord insertion. 


\section{References}

1. Hasegawa J, Matsuoka R, Ichizuka K, et al. Velamentous cord insertion: Significance of prenatal detection to predict perinatal complications. Taiwanese J Obstet Gynecol 2006;45(1):21-25. DOI: 10.1016/S1028-4559(09)60185-6

2. SepulvedaW, Rojas I, RobertJA, etal. Prenatal detection of velamentous insertion of the umbilical cord: a prospective color Doppler ultrasound study. Ultrasound Obstet Gynecol 2003;21(6):564-569. DOI: $10.1002 /$ uog. 132

3. Tenkumo C, Hanaoka U, AboEllail MAM, et al. HDlive Flow with HDlive silhouette mode in diagnosis of fetal hepatic hemangioma. Ultrasound Obstet Gynecol 2017;49(4):540-545. DOI: 10.1002/uog.16215
4. Ganjiguur TO, AboEllail MAM, Mori N, et al. HDlive Flow with HDlive silhouette mode for diagnosis of persistent right umbilical vein and single umbilical artery. Donald School J Ultrasound Obstet Gynecol 2018;12(1):1-3. DOI:10.5005/jp-journals-10009-1545

5. Yang PY, Kanenishi K, Ishibashi M, et al. HDlive Flow with HDlive silhouette mode in antenatal diagnosis of bilobed placenta. Donald School J Ultrasound Obstet Gynecol 2016;10(4):415-417. DOI:10.5005/jp-journals-10009-1495

6. Markov D, Ivanov $S$, Markov $P$, et al. Velamentous insertion of the umbilical cord-diagnosis and management. Akush Ginekol (Sofia) 2009;48(5):3-10. 